\title{
Endothelin A-receptors and the coronary circulation
}

\author{
Evangelos Polymeropoulos ${ }^{1}$, Mesele Valenti ${ }^{1}$, Zenon S. Kyriakides ${ }^{1,2^{*}}$ \\ ${ }^{1}$ 2nd Department of Cardiology, Hellenic Red Cross General Hospital, Athens, Greece \\ ${ }^{2}$ Cardiovascular Research Institute, Athens, Greece \\ Email: zskyr@otenet.gr
}

Received 3 June 2013; revised 3 July 2013; accepted 20 July 2013

Copyright (C) 2013 Evangelos Polymeropoulos et al. This is an open access article distributed under the Creative Commons Attribution License, which permits unrestricted use, distribution, and reproduction in any medium, provided the original work is properly cited.

\begin{abstract}
We review the role of endothelin (ET) A-receptors (R) on the coronary circulation. ET-1 maintains the normal coronary artery tone. ET-1 plasma levels are increased during and after coronary angioplasty and this increase is related to myocardial ischaemia rather than to mechanical artery injury. $\mathrm{ET}_{\mathrm{A}} \mathrm{R}$ antagonists inhibit coronary artery vasoconstriction induced by ET release after coronary angioplasty in humans. ET promotes neointimal formation and $\mathrm{ET}_{\mathrm{A}} \mathrm{R}$ antagonism has been shown to inhibit restenosis after angioplasty in the animal model but not in humans. ET $_{A} R$ blockade increases coronary blood flow, dilates distal coronary arterial segments and decreases coronary vascular resistance. Coronary collaterals are less sensitive than other coronary vessels to ET-1. ET $_{A} R$ blockade decreases collateral blood flow and, consequently, perfusion of the ischemic myocardium.
\end{abstract}

Keywords: Endothelin; Coronary Circulation

\section{INTRODUCTION}

Diseases of the cardiovascular system account for the majority of morbidity and mortality in Western countries. Most forms of cardiovascular disease are associated with impaired vascular function in the cerebral, coronary, renal or peripheral circulation. Enhanced intermittent and/ or persistent vasoconstriction is one of the most important features of several forms of cardiovascular disease.

An important local vascular regulator is the 21-amino acid peptide endothelin (ET) with potent and characteristically sustained vasoconstrictor and vasopressor actions [1]. In the blood vessel wall, only endothelial cells produce the peptide and exclusively ET-1, except in disease states such as atherosclerosis, where smooth muscle cells may also contribute. Most of the ET-1 produced in the

"Corresponding author. endothelium interacts with vascular smooth muscles, while only about one-third circulates and can be measured by radioimmunoassay techniques [2].

With intraluminal administration of ET-1, a transient vasodilation due to activation of nitric oxide and prostacyclin is observed followed by profound and sustained vasoconstriction which is mediated by $\mathrm{ET}_{\mathrm{A}} \mathrm{R}$ receptor activation and at least in certain blood vessels also by $\mathrm{ET}_{\mathrm{B}} \mathrm{R}$ receptors $[3,4]$. With higher concentrations of ET-1, only vasoconstriction is observed, although even then inhibition of a production of endothelium derived relaxing factors enhances the response to the peptide [5].

Brunner [6] compared coronary and interstitial ET-1 levels in perfused rat hearts under several experimental conditions. Basal ET-1 releasing into effluent was higher than in transudate, but basal ET-1 concentration was four-fold higher in transudate than in effluent. Following the removal of the endothelial cells, ET-1 release in the artery lumen decreased dramatically and was completely abolished in interstitial transudate, indicating that the peptide originated from the vascular endothelium [6]. When the coronary flow was reduced to an ischemic level, ET-1 secretion rates into effluent decreased by $60 \%$, but increased 3- to 4-fold after reperfusion at normal flow. These data do not support a vasoconstrictor action of ET-1 in rats following ischemia/reperfusion, but rather point to a possible vasodilator role of the peptide under these conditions.

Thrombin and ischemia increase ET-1 production and up-regulate its receptors. In patients with unstable angina, increased staining for ET-1 can be demonstrated in coronary artery lesions removed by atherectomy [7]. ET-1 levels were measured in blood samples, obtained from the femoral vein of patients with stable angina, undergoing coronary rotational atherectomy. Patients undergoing plain balloon angioplasty were used as controls. Plasma levels of ET-1 were higher in patients undergoing balloon angioplasty, whereas in patients undergoing 
atherectomy, these were only mildly elevated [8] (Figure 1). The peripheral release of ET-1 during angioplasty is related to myocardial ischemia, rather than to endothelial injury [9] (Figure 2). Possible explanations for the smaller ET-1 secretion during atherectomy compared with balloon angioplasty are: 1) more calcified arteries may secrete less ET-1 during ischemia; 2) more diffusely diseased arteries may produce less ET-1 during ischemia, and 3) the destruction of the endothelium during rotational atherectomy is so extensive that it renders itself unable to produce and excrete ET-1 into the plasma.

Tahara, et al. [10] reported that ET-1 is increased in the coronary sinus after coronary angioplasty. ET-1 plasma levels have been shown to increase more in normotensive than in hypertensive patients after coronary angioplasty [11]. Thus, ET-l has a weaker vasomotor effect on the coronary vasculature in hypertensive patients than in normotensives [12], due to reduced responsiveness to ET-l by the small resistance arteries in the former. In patients undergoing angioplasty, ET-1 is increased more in patients with partially occluded coronary arteries than in patients with totally occluded vessels. Thus, the increase in ET-1 is another confirmation that ET-1 levels are related to myocardial ischaemia rather than to mechanical artery injury [9].

Biopsies from internal mammary arteries in patients undergoing coronary artery by-pass grafting showed that systemic hypertension is associated with increased ET-1 and $\mathrm{ET}_{\mathrm{A}} \mathrm{R}$ receptor mRNA expression, whereas insulin-dependent diabetes down-regulates $\mathrm{ET}_{\mathrm{A}} \mathrm{R}$ receptor mRNA expression [13]. This could help explain the differential response of hypertensive and diabetic animals and humans to external and internal stimulation and blockade of ET-1 and its receptors.

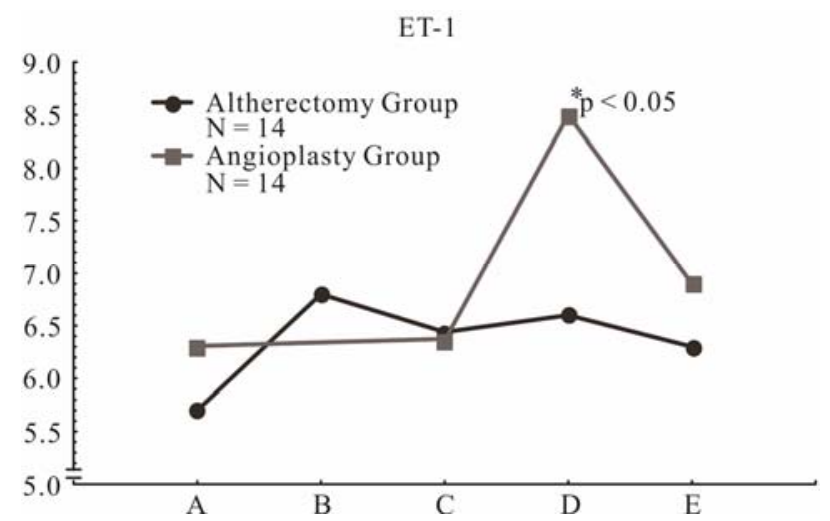

Figure 1. Plasma levels of Endotelin-1 were higher in patients undergoing balloon angioplasty, whereas in patients undergoing atherectomy, these were insignificantly raised. Letters A to E denote the phases during which blood samples were drawn. A is after the coronary artery engagement with the guiding catheter (baseline), B is after the end of the rotational atherectomy, C is after the first balloon inflation, $\mathrm{D}$ is immediately after the end of the procedure, and $\mathrm{E}$ is 4 hours later [8].

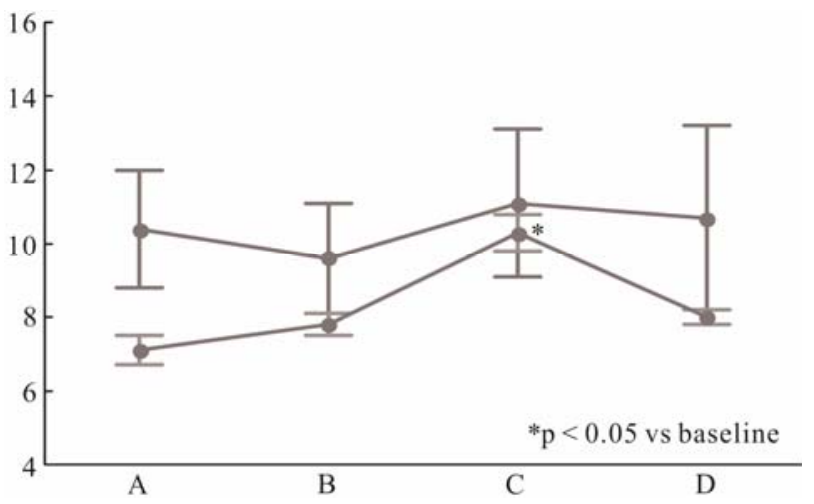

Figure 2. Endothelin-1 during coronary angioplasty in a group of patients with total (filled circles) and another with partial (open circles) artery occlusion $*<0.05$ vs baseline. Letters A to $\mathrm{D}$ denote the phases during which blood samples were drawn. $\mathrm{A}$ is after the coronary artery engagement with the guiding catheter (baseline), B is after the first balloon inflation, C is immediately after the end of the procedure, and D is 4 hours later [9].

\section{ET-1 DURING ANGIOPLASTY}

In a study utilizing the selective $\mathrm{ET}_{\mathrm{A}} \mathrm{R}$ antagonist BQ-123 in patients undergoing angioplasty [14], acute $\mathrm{ET}_{\mathrm{A}} \mathrm{R}$ receptor antagonism prevented the normal reducetion of myocardial ischemia on repeated balloon inflations. This phenomenon may be explained by a "steal" effect through coronary collaterals; local $\mathrm{ET}_{\mathrm{A}} \mathrm{R}$ receptor antagonism with BQ-123 causes coronary vasodilatation (mainly at the distal coronary arterial segments), an increase in coronary blood flow, and a decrease in the coronary artery resistance [14] (Figure 3). $\mathrm{ET}_{\mathrm{A}} \mathrm{R}$ receptor antagonism may increase coronary blood flow and decrease coronary artery resistance and distal coronary pressure by dilating the distal arterial segments and the resistance arteries in the non-ischemic region and increasing coronary blood flow [15] (Figure 4).

Coronary vasoconstriction after coronary angioplasty has been attributed to a variety of mechanisms and it can be prevented by $\mathrm{ET}_{\mathrm{A}}$ receptor blockade. Quantitative analysis of coronary angiography of the diameter of the distal segment of coronary arteries 25 minutes after coronary angioplasty, showed that intracoronary administration of BQ-123 hindered vasoconstriction of the distal segment [16] (Figure 5).

\section{ET ANTAGONISTS IN CORONARY BLOOD FLOW}

ET-1 and big ET-1 administration in rat hearts reduces coronary blood flow. However, BQ-123, an $\mathrm{ET}_{\mathrm{A}} \mathrm{R}$ receptor antagonist abolishes the cardiac effect of ET-1 [17]. Cannan, et al. [18] showed that low concentrations of exogenous ET-1 in dogs, which may mimic pathophysiological concentrations, result in coronary vasoconstriction mediated predominantly via the $\mathrm{ET}_{\mathrm{A}} \mathrm{R}$, since such 


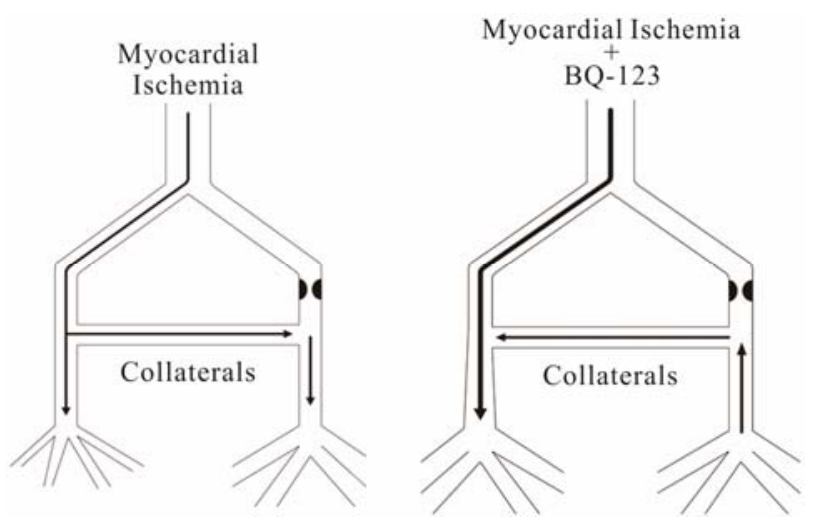

Figure 3. Schematic representation of coronary arterial bed, effects of myocardial ischemia, and possible effects of $\mathrm{ET}_{\mathrm{A}} \mathrm{R}$ antagonism (BQ-123). Coronary arteries can be divided into 2 functional components: large epicardial conductance arteries and smaller resistance arterioles. After significant narrowing of coronary artery, ischemic stimulus results in autoregulation of small resistance vessels and consequently maximal vasodilation in ischemic region. $\mathrm{ET}_{\mathrm{A}} \mathrm{R}$ antagonism, in nonischemic region, dilates distal arterial segments and resistance vessels, causing decrease in coronary artery resistance, increase in blood flow, and fall in distal coronary pressure. Fall in pressure at source of collaterals may diminish collateral flow and perfusion of ischemic myocardium. This deleterious effect is termed "coronary steal” [14].
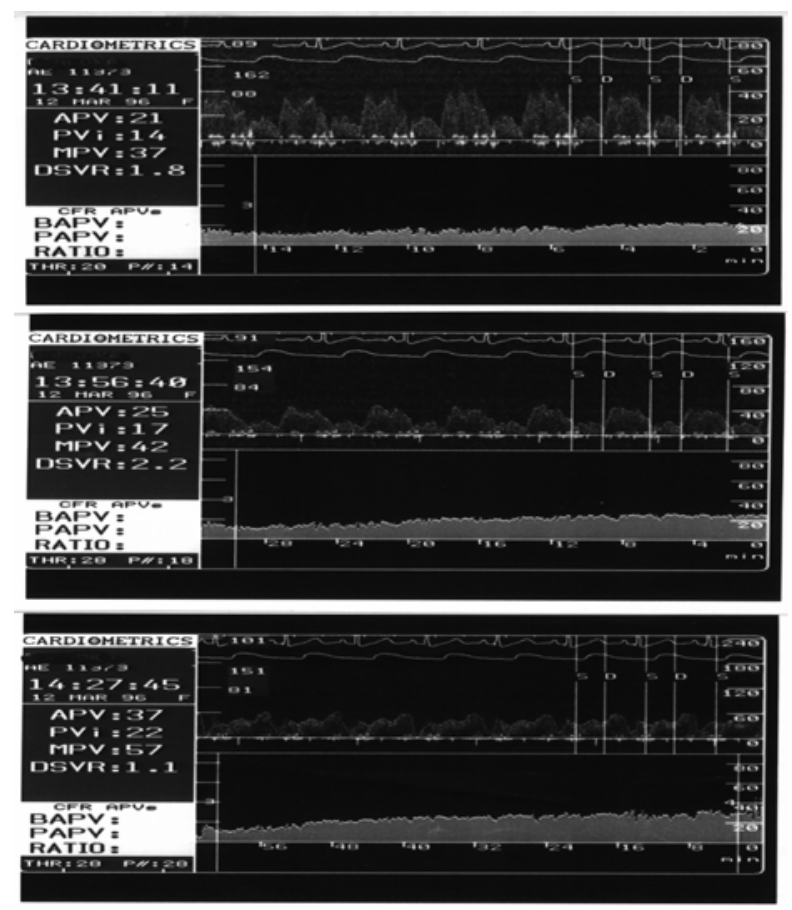

Figure 4. Coronary blood flow velocity in a patient with coronary artery disease 15 minutes (top) and 30 minutes (middle) after the initiation of $\mathrm{BQ}-123$, an $\mathrm{ET}_{\mathrm{A}} \mathrm{R}$ blocker, infusion and after the end of the infusion (bottom). It can be seen that peak velocity integral (PVI) increases from 14 to 17 and $22 \mathrm{~cm}$, respectively, while systolic blood pressure decreases from 162 to 154 and $151 \mathrm{~mm} \mathrm{Hg}$. Note that the blood flow velocity scale is different in the three recordings [15].
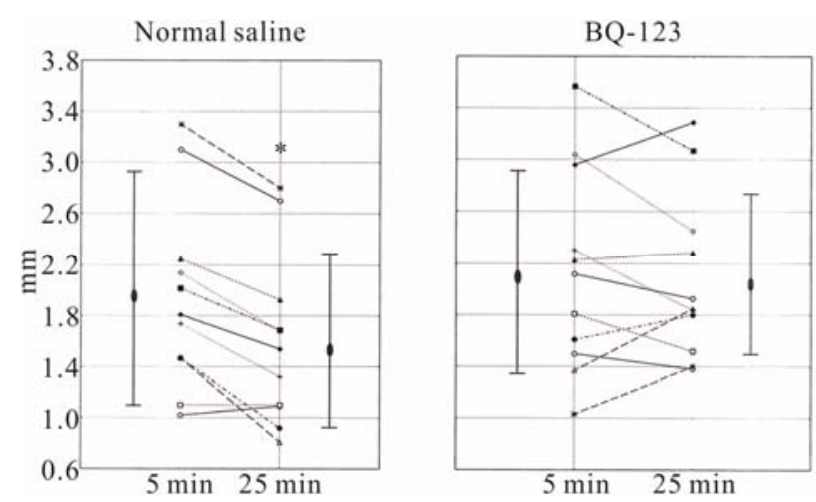

Figure 5. Line plots of the diameter of the distal arterial segments at 5 and 25 minutes after completion of angioplasty with BQ-123 (an $\mathrm{ET}_{\mathrm{A}} \mathrm{R}$ antagonist) (right) or saline control administration (left). *: p $<0.05$ versus 5-minute postangioplasty [16].

vasoconstriction is significantly attenuated by $\mathrm{ET}_{\mathrm{A}} \mathrm{R}$ blockade. Pernow, et al. [19] showed that intravenous ET-1 administration decreases coronary sinus blood flow and increases coronary vascular resistance in humans.

Endogenous ET-1 maintains the normal coronary artery tone and thus regulates coronary blood flow. In patients undergoing coronary arteriography, administration of intracoronary BQ-123 led to an increase in blood flow in the left anterior descending coronary artery, an increase in the diameter of the distal segment of the coronary artery and a decrease in coronary vascular resistance (Figure 4) [15]. Moreover, changes in blood flow were similar in subjects with and without coronary artery disease [15]. In coronary artery disease patients, coronary artery compliance increased after intracoronary BQ-123 [20]. $\mathrm{ET}_{\mathrm{A}} \mathrm{R}$ dependent activity is impaired in diabetic patients; coronary artery diameter in diabetic patients increased far less in comparison to healthy subjects after administration of intracoronary BQ-123 [21]. In a similar manner, physiologic response to $\mathrm{ET}_{\mathrm{A}} \mathrm{R}$ blockade was also attenuated in hypertensive patients [22].

\section{ET-1 ON THE CORONARY COLLATERAL CIRCULATION}

Collateral vessels demonstrate heightened sensitivity to certain vasoconstrictors such as vasopressin, which can decrease blood flow to the dependent myocardium at doses that do not affect blood flow to normal myocardium. Rapps, et al. [23] found that collateral vessel rings constricted smaller-than-normal coronary arterial vessels to ET-1. An impaired collateral vasoconstrictor response might be expected to protect collateral blood flow when ET-1 levels are increased. In the work of Traverse, et al. [24], collateral blood flow did not significantly change although coronary sinus ET-1 concentrations exceeded $70 \mathrm{pg} / \mathrm{ml}$. Only at the highest infusion rate, when the coronary blood concentration was $175 \mathrm{pg} / \mathrm{ml}$, did colla- 
teral blood flow decrease significantly. It was demonstrated that in the intact animal collateral vessels constrict similarly to normal vessels in response to ET-1.

Coronary collateral vessels can synthesise prostacyclin. Furthermore, in dogs with long-term coronary occlusion, prostacyclin appears to cause tonic collateral vessel dilatation [25] because cyclooxygenase blockade with indomethacin significantly decreased retrograde blood flow from the cannulated collateral dependent artery. Traverse, et al. [24] showed that prostacyclin production is important in blunting the vasoconstrictor effects of ET-1 in the collateral circulation. In contrast, the response of collateral vascular resistance to ET-1 in the normal zone was much less affected by inhibition of prostacyclin production. This is in agreement with previous findings that vasodilator prostaglandins are of greater importance in collateral than in normal coronary vessels.

Well-developed collateral vessels exhibit nitric oxidemediated, endothelium-dependent vasodilation in response to agonists such as acetylcholine or bradykinin [26-28]. However, there are indications that vasodilatation of collateral vessels resulting from ET-1-stimulated production of nitric oxide could also improve perfusion of the collateral-dependent region. ET-1 could alter blood flow to the collateral-dependent myocardium by influencing vasomotion of the resistance vessels in the collateral zone. As we know, receptor-mediated, endothelium-dependent dilation has been shown to be impaired in microvessels chronically perfused by collateral vessels [28].

Donckier, et al. [29] studied 30 conscious chronically instrumented dogs before, during and after a 10-min coronary artery occlusion performed either during ET-1 or during saline infusion. Left anterior descending artery blood flow decreased equally during occlusion with either ET-1 or saline. Both endocardial and epicardial blood flow in ischemic regions also decreased during artery occlusion but were threefold greater with ET-1 than with placebo. These results showed that ET-1 increases collateral blood flow in the ischemic myocardium in dogs.

By combining coronary wedge pressure, obtained by means of a wave wire, with simultaneously recorded aortic pressure, obtained by means of the guiding catheter, and central venous pressure at maximum arterial vasodilation, a quantitative index of collateral flow can be calculated. This index, called fractional collateral blood flow, expresses actual collateral flow as a ratio to normal maximum myocardial perfusion. A lower ratio indicates a higher impairment in the collateral perfusion of the ischemic myocardium. After repeated balloon inflations, the coronary wedge pressure, in a group of patients administered BQ-123, decreased, whereas in the control group it increased. These results indicate that acute $\mathrm{ET}_{\mathrm{A}} \mathrm{R}$ antagonism decreases coronary collateral circulation in patients with coronary artery disease during angioplasty. Therefore, $\mathrm{ET}_{\mathrm{A}} \mathrm{R}$ antagonism may increase coronary blood flow and decrease coronary artery resistance and distal coronary pressure by dilating the distal arterial segments and the resistance arteries in the nonischemic region [14].

\section{ETA ANTAGONISTS AND INHIBITION OF RESTENOSIS}

In addition to its actions on vascular smooth muscle cells, ET-1 is also a potent mitogen in several cultured cell lines of both cardiovascular and noncardiovascular origin [30]. ET-1 also induces the expression and release of several proto-ongogenes and growth factors, the latter of which may be synergistic [31-34].

Douglas, et al. [35] studied the role of endogenous ET-1 in neointimal formation after rat carotid artery balloon angioplasty. They showed that ET-1 promotes neointimal formation in vivo and that it is involved in the pathogenesis of angioplasty-induced lesion formation in the rat. They showed also the protective effect of the nonpeptide ETR antagonist SB $209670\left(\mathrm{ET}_{\mathrm{A}} \mathrm{R}\right.$ and $\mathrm{ET}_{\mathrm{B}} \mathrm{R}$ antagonist) in neointimal formation, indicating that this substance can serve as a useful adjunct to coronary angioplasty, attenuating the degree of vascular restenosis observed after vascular wall injury. The same investigators showed that neither chronic nor acute $\mathrm{ET}_{\mathrm{A}} \mathrm{R}$ blockade after giving $\mathrm{BQ}-123$, an $\mathrm{ET}_{\mathrm{A}} \mathrm{R}$ blockade, is sufficient to inhibit angioplasty-induced neointima formation in the rat. They implicated a significant role for the $\mathrm{ET}_{\mathrm{B}} \mathrm{R}$ subtype, either exclusively or in concert with $\mathrm{ET}_{\mathrm{A}} \mathrm{R}$ activation, in the pathogenesis of neointima formation in the rat. The administration of BQ-123 in patients with stable angina undergoing angioplasty, failed to show any difference in restenosis after 6 months, as analyzed by quantitative coronary arteriography and intravascular ultrasound [36].

\section{CONCLUSION}

ET-1 maintains normal coronary artery tone. $\mathrm{ET}_{\mathrm{A}} \mathrm{R}$ assume a cornerstone role on the regulation of coronary circulation. There is an upregulation of $\mathrm{ET}_{\mathrm{A}} \mathrm{R}$ in hypertension and a downregulation in diabetes. $\mathrm{ET}$ is a potent promoter of neointimal formation, and $\mathrm{ET}_{\mathrm{A}} \mathrm{R}$ blockade inhibits restenosis after angioplasty in animal model. The secretion of ET during myocardial ischemia and reperfusion is related to ischemia, rather than to endothelial injury. $\mathrm{ET}_{\mathrm{A}} \mathrm{R}$ antagonism increases coronary blood flow in healthy coronary arteries, but may reduce coronary blood flow in diseased segments, via a coronary steal phenomenon. Moreover, $\mathrm{ET}_{\mathrm{A}} \mathrm{R}$ blockade increases the diameter of distal coronary arterial segments and decreases coronary vascular resistance. Coronary collaterals have decreased sensitivity to ET-1, and $\mathrm{ET}_{\mathrm{A}} \mathrm{R}$ antagonism de- 
creases collateral blood flow and perfusion of the ischemic myocardium.

\section{REFERENCES}

[1] Yanagisawa, M., Kurihara, H., Kimura, S., Tomobe, Y., Kobayashi, M., Mitsui, Y., et al. (1988) A novel potent vasoconstrictor peptide produced by vascular endothelial cells. Nature, 332, 411-415. doi:10.1038/332411a0

[2] Wagner, O.F., Christ, G., Wojta, J., Vierhapper, H., Parzer, S., Nowotny, P.J., et al. (1992) Polar secretion of endothelin-1 by cultured endothelial cells. The Journal of Biological Chemistry, 267, 16066-16068.

[3] Kiowski, W., Luscher, T.F., Linder, L. and Buhler, F.R. (1991) Endothelin-1-induced vasoconstriction in humans. Reversal by calcium channel blockade but not by nitrovasodilators or endothelium-derived relaxing factor. Circulation, 83, 469-475. doi:10.1161/01.CIR.83.2.469

[4] Seo, B., Oemar, B.S., Siebenmann, R., Von, S.L. and Luscher, T.F. (1994) Both ETA and ETB receptors mediate contraction to endothelin-1 in human blood vessels. Circulation, 89, 1203-1208. doi:10.1161/01.CIR.89.3.1203

[5] Luscher, T.F., Yang, Z., Tschudi, M., Von, S.L., Stulz, P., Boulanger, C., et al. (1990) Interaction between endothelin-1 and endothelium-derived relaxing factor in human arteries and veins. Circulation Research, 66, 10881094. doi:10.1161/01.RES.66.4.1088

[6] Brunner, F. (1995) Tissue endothelin-1 levels in perfused rat heart following stimulation with agonists and in ischaemia and reperfusion. Journal of Molecular and Cellular Cardiology, 27, 1953-1963. doi:10.1016/0022-2828(95)90017-9

[7] Zeiher, A.M., Goebel, H., Schachinger, V. and Ihling, C. (1995) Tissue endothelin-1 immunoreactivity in the active coronary atherosclerotic plaque. A clue to the mechanism of increased vasoreactivity of the culprit lesion in unstable angina. Circulation, 91, 941-947. doi:10.1161/01.CIR.91.4.941

[8] Kyriakides, Z.S., Markianos, M., Antoniadis, A., Sbarouni, E., Nikolaou, N., Zarvalis, E., et al. (1998) Effect of rotational coronary atherectomy on peripheral endothelin-1, atrial natriuretic peptide, and cyclic adenosine monophosphate plasma levels. Cardiovascular Drugs and Therapy, 12, 245-250. doi:10.1023/A:1007709614835

[9] Kyriakides, Z.S., Markianos, M., Iliodromitis, E.K. and Kremastinos, D.T. (1995) Vein plasma endothelin-1 and cyclic GMP increase during coronary angioplasty is related to myocardial ischaemia. European Heart Journal, 16, 894-898.

[10] Tahara, A., Kohno, M., Yanagi, S., Itagane, H., Toda, I., Akioka, K., et al. (1991) Circulating immunoreactive endothelin in patients undergoing percutaneous transluminal coronary angioplasty. Metabolism, 40, 1235-1237. doi:10.1016/0026-0495(91)90021-N

[11] Kyriakides, Z.S., Markianos, M., Paraskevaidis, I.A., Tousoulis, D., Fragakis, N.K. and Kremastinos, D.T.
(1996) Decreased vasomotor effect of endothelin on the coronary arteries during angioplasty in hypertensive patients. International Journal of Cardiology, 55, 41-48. doi:10.1016/0167-5273(96)02653-8

[12] Schiffrin, E.L., Deng, L.Y. and Larochelle, P. (1992) Blunted effects of endothelin upon small subcutaneous resistance arteries of mild essential hypertensive patients. Journal of Hypertension, 10, 437-444. doi:10.1097/00004872-199205000-00006

[13] Zygalaki, E., Kaklamanis, L., Lolaka, M., Nikolaou, N., Koutouzis, M., Lianidou, E.S., et al. (2009) Systemic hypertension augments, whereas insulin-dependent diabetes down-regulates, endothelin A-receptor expression in the mammary artery in coronary artery disease patients. Cardiology Journal, 16, 348-354.

[14] Kyriakides, Z.S., Kremastinos, D.T., Kolettis, T.M., Tasouli, A., Antoniadis, A. and Webb, D.J. (2000) Acute endothelin A-receptor antagonism prevents normal reduction of myocardial ischemia on repeated balloon inflations during angioplasty. Circulation, 102, 1937-1943. doi:10.1161/01.CIR.102.16.1937

[15] Kyriakides, Z.S., Kremastinos, D.T., Bofilis, E., Tousoulis, D., Antoniadis, A. and Webb, D.J. (2000) Endogenous endothelin maintains coronary artery tone by endothelin type A-receptor stimulation in patients undergoing coronary arteriography. Heart, 84, 176-182. doi:10.1136/heart.84.2.176

[16] Kyriakides, Z.S., Kremastinos, D.T., Psychari, S.N., Kolettis, T., Sbarouni, E. and Webb, D.J. (2001) Coronary vasoconstriction after coronary angioplasty is attenuated by endothelin a receptor antagonism. American Journal of Cardiology, 87, 1011-1013. doi:10.1016/S0002-9149(01)01441-2

[17] Grover, G.J., Sleph, P.G., Fox, M. and Trippodo, N.C. (1992) Role of endothelin-1 and big endothelin-1 in modulating coronary vascular tone, contractile function and severity of ischemia in rat hearts. Journal of Pharmacology and Experimental Therapeutics, 263, 1074-1082.

[18] Cannan, C.R., Burnett, Jr. J.C., , Brandt, R.R. and Lerman, A. (1995) Endothelin at pathophysiological concentrations mediates coronary vasoconstriction via the endothelin-A receptor. Circulation, 92, 3312-3317. doi:10.1161/01.CIR.92.11.3312

[19] Pernow, J., Kaijser, L., Lundberg, J.M. and Ahlborg, G. (1996) Comparable potent coronary constrictor effects of endothelin-1 and big endothelin-1 in humans. Circulation, 94, 2077-2082. doi:10.1161/01.CIR.94.9.2077

[20] Kyriakides, Z.S., Kremastinos, D.T., Kolokathis, F., Kostopoulou, A., Georgiadis, M. and Webb, D.J. (2002) Acute endothelin (A) receptor antagonism improves coronary artery compliance in coronary artery disease patients. Clinical Science (London), 103, S179S-S183S.

[21] Kyriakides, Z.S., Kremastinos, D.T., Raptis, A.E., Johnston, N., Raptis, S.A., Webb, D.J., et al. (2006) Impaired effect of endothelin-1 on coronary artery stiffness in type 2 diabetes. International Journal of Cardiology, 112, 207-212. doi:10.1016/j.ijcard.2005.09.018

[22] Kyriakides, Z., Kyrzopoulos, S., Paraskevaidis, I., Kolokathis, F., Tsopotos, I., Lyras, T., et al. (2004) Endothe- 
lin-A receptor antagonism promotes decreased vasodilation but has no differential effect on coronary artery compliance in hypertensive patients. Journal of Cardiovascular Pharmacology, 44, S85-S88. doi:10.1097/01.fjc.0000166209.19921.fC

[23] Rapps, J.A., Jones, A.W., Sturek, M., Magliola, L. and Parker, J.L. (1997) Mechanisms of altered contractile responses to vasopressin and endothelin in canine coronary collateral arteries. Circulation, 95, 231-239. doi:10.1161/01.CIR.95.1.231

[24] Traverse, J.H., Judd, D. and Bache, R.J. (1996) Dose-dependent effect of endothelin-1 on blood flow to normal and collateral-dependent myocardium. Circulation, 93, 558-566. doi:10.1161/01.CIR.93.3.558

[25] Altman, J., Dulas, D. and Bache, R.J. (1992) Effect of cyclooxygenase blockade on blood flow through welldeveloped coronary collateral vessels. Circulation Research, 70, 1091-1098. doi:10.1161/01.RES.70.6.1091

[26] Angus, J.A., Ward, J.E., Smolich, J.J. and McPherson, G.A. (1991) Reactivity of canine isolated epicardial collateral coronary arteries. Relation to vessel structure. Circulation Research, 69, 1340-1352. doi:10.1161/01.RES.69.5.1340

[27] Flynn, N.M., Kenny, D., Pelc, L.R., Warltier, D.C., Bosnjak, Z.J. and Kampine, J.P. (1991) Endothelium-dependent vasodilation of canine coronary collateral vessels. American Journal of Physiology, 261, H1797-H1801.

[28] Sellke, F.W., Quillen, J.E., Brooks, L.A. and Harrison, D.G. (1990) Endothelial modulation of the coronary vasculature in vessels perfused via mature collaterals. Circulation, 81, 1938-1947. doi:10.1161/01.CIR.81.6.1938

[29] Donckier, J., Hanet, C., Stoleru, L., Van, M.H., Galanti, L., Hayashida, W., et al. (1994) Effects of endothelin-1 at pathophysiologic concentrations on coronary perfusion and mechanical function of normal and postischemic myocardium. Journal of Cardiovascular Pharmacology, 23, 212-219. doi:10.1097/00005344-199402000-00006

[30] Ohlstein, E.H., Arleth, A., Bryan, H., Elliott, J.D. and
Sung, C.P. (1992) The selective endothelin ETA receptor antagonist BQ123 antagonizes endothelin-1-mediated mitogenesis. European Journal of Pharmacology: Molecular Pharmacology, 225, 347-350. doi:10.1016/0922-4106(92)90109-9

[31] Bobik, A., Grooms, A., Millar, J.A., Mitchell, A. and Grinpukel, S. (1990) Growth factor activity of endothelin on vascular smooth muscle. American Journal of Physiology, 258, C408-C415.

[32] Hirata, Y., Takagi, Y., Fukuda, Y. and Marumo, F. (1989) Endothelin is a potent mitogen for rat vascular smooth muscle cells. Atherosclerosis, 78, 225-228. doi:10.1016/0021-9150(89)90227-X

[33] Jaffer, F.E., Knauss, T.C., Poptic, E. and Abboud, H.E. (1990) Endothelin stimulates PDGF secretion in cultured human mesangial cells. Kidney International, 38, 11931198. doi:10.1038/ki.1990.333

[34] Komuro, I., Kurihara, H., Sugiyama, T., Yoshizumi, M., Takaku, F. and Yazaki, Y. (1988) Endothelin stimulates c-fos and c-myc expression and proliferation of vascular smooth muscle cells. FEBS Letters, 238, 249-252. doi:10.1016/0014-5793(88)80489-7

[35] Douglas, S.A., Vickery-Clark, L.M., Louden, C., Elliott, J.D. and Ohlstein, E.H. (1995) Endothelin receptor subtypes in the pathogenesis of angioplasty-induced neointima formation in the rat: A comparison of selective ETA receptor antagonism and dual ETA/ETB receptor antagonism using BQ-123 and SB 209670. Journal of Cardiovascular Pharmacology, 26, S186-S189.

[36] Kyriakides, Z.S., Psychari, S.N., Kolettis, T.M., Georgiadis, M., Antoniadis, A. and Kremastinos, D.T. (2003) Usefulness of endothelin (A) receptor antagonists for the prevention of in-stent restenosis in patients with stable angina pectoris or silent myocardial ischemia. American Journal of Cardiology, 91, 476-479. doi:10.1016/S0002-9149(02)03253-8 